\title{
12 \\ Building up a virtual organisation
}

\author{
D. Brütsch
}

Assistant in the group of Prof. Dr. P. Schönsleben

Institute for Industrial Engineering and Management (BWI),

Swiss Federal Institute of Technology (ETH) Zurich, $\mathrm{CH}$

Phone: +41-1-63205 32, Fax: +41-1-632 1040

bru@bwi.bepr.ethz.ch

\begin{abstract}
This report characterises the concept of virtual organisation from the point of view of the network trend. In order to investigate the factors for success for the creation of a virtual organisation and to scrutinise closely a relationship within a network one must draw on the transaction cost model. Further, the partners and the goals of the VIRTUOS ("Virtuelles Unternehmen in Österreich und der Schweiz") Project are introduced more closely. In closing, the present state of the project and the measures implemented thus far will be inspected.
\end{abstract}

\section{Keywords}

Virtual organisation, networks, logistics, supply chain management, implementation, wood industry.

\section{INTRODUCTION}

The increasing globalisation of the market place and the improved spatial and temporal availability of information, as well as increased competition, have lead to a rapid change in clients needs. The repletion of the market, or the tendency to a buyer's market forces the company to react increasingly faster and more flexibly to those changing needs.

Clients no longer demand alternatively, but rather simultaneously, minimal delivery times, high flexibility and quality, and low price. Due to the increasing complexity of the establishment of service and the mounting dynamics of the 
economic environment, the ability of a company becomes increasingly more important. This ability or competence contains on the one hand special core abilities that define the basic service of a company. One the other hand a company must display other things, like for example the ability to co-operate. Exactly because a concentration of core abilities is taking place, at the present time the complete net product is no longer produced in-house, which means that the ability to co-operate becomes a critical factor for success.

A present example of this is the formation of the "Star Alliance" between Lufthansa German Airlines, United Airlines, SAS, Air Canada, and Thai Airways. During the formation it was clearly stated that this was not a preliminary step towards a merger and that the partners did not strive towards a mutual participation. Costs can nevertheless be reduced through improved co-operation in sales or in dispatch. Thus it becomes clear that increasingly companies are outsourcing or running common services (e.g. check-in), which do not have an impact on the core business, together with other companies.

This example shows that the attractiveness of network organisations lies on the one hand in concentrating on specific abilities and on the other hand on a network that is as efficient as possible. In this point a rapid development in the IT area also plays a role, since the increasingly efficient and interactive systems make an exchange of information possible to meet the demand needed by the network organisations.

\section{CHARACTERISTICS OF A VIRTUAL ORGANISATION}

As a special form of network we single out the virtual organisation. Since the subject is topical at the moment and comparisons to existing network forms are often sought, there are a large number of definitions. For example:

- "The virtual corporation is a temporary network of independent companies, suppliers, customers, even erstwhile rivals - linked by information technology to share skills, costs and access to one another's markets. It will have neither central office nor organisation chart. It will have no hierarchy, no vertical integration... In the concepts purest form, each company that links up with others to create a virtual corporation will be stripped to its essence. It will contribute only what it regards as its core competencies" (Davidow and Malone 1992).

- "Within a holonic network, any company, large or small, can exploit its core competencies by linking them with competencies of other companies. This occurs in virtual companies. The virtual company creates the best core business process possible and manages the critical path in real time. But in this network, there must be totally open communication and total trust" (McHugh 1995). 
From these and further definitions emerges, that the virtual organisation is something dynamic and combines the best abilities according to market requirements. In order to work out wherein the new aspects of a virtual organisation lie, the two main elements network and virtual enterprise (Brütsch and FrigoMosca 1996) are depicted by the following diagram (Figure 1):

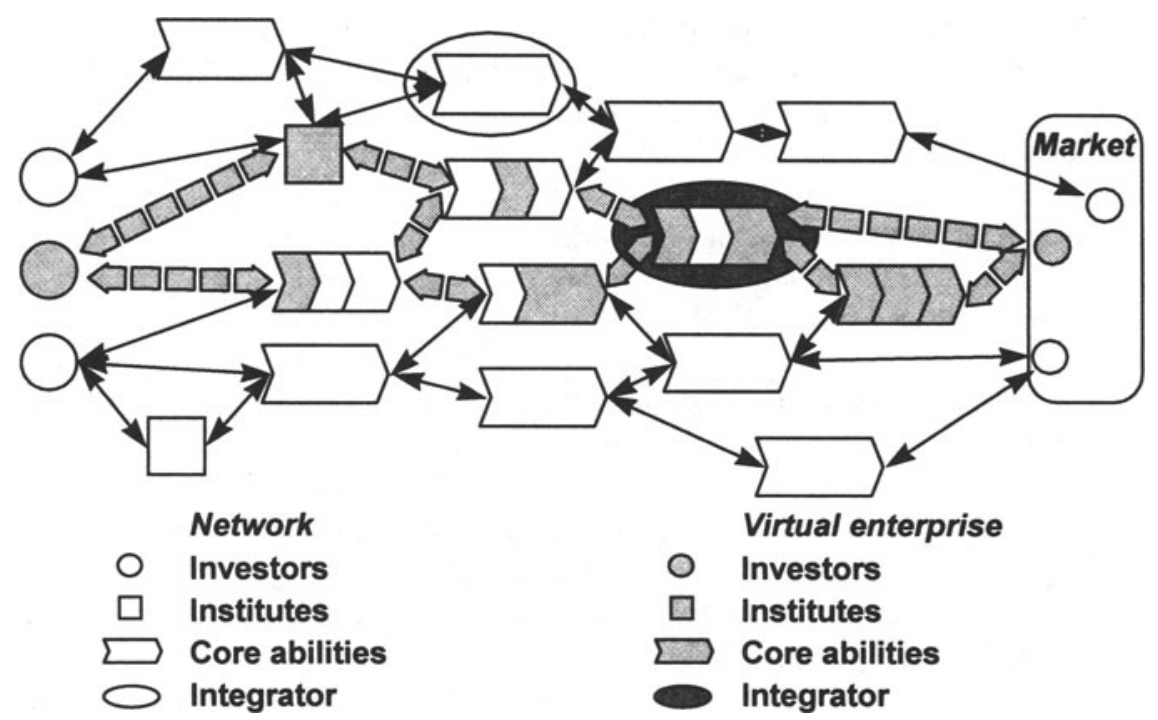

Figure 1 Two main elements of a virtual organisation.

The main element Network rests upon a long-term collaboration and consists of investors, institutes, core abilities and integrators (i.e. mediators between companies or organisations with marketing functions). In this network no services are generated, but rather an environment of trust is created and fostered through common meetings and contacts.

The main element virtual enterprise is made up of single network participants as necessary. The starting point is usually the integrator, who co-ordinates the employment and services of the other participants. The newly formed company produces a concrete client-specific service, as long as the market for it exists. At the end of the service's life-cycle the company is dissolved and each network participant is free for new jobs.

\subsection{Advantages and disadvantages of a virtual organisation}

A virtual organisation is a very interesting alternative to normal structures and organisations. The following lists the advantages: 
- the creation of synergism through the combination of core abilities between the participants.

- if speed is coupled with adequate organisational measures (simultaneous engineering, teamwork) the "time-to-market" can be drastically reduced.

- distribution of risk, specifically also in case of capacity overload, in which the companies distribute parts of their order to other members.

- independence, i.e. the possibility to leave the network at any time.

- catering to individual client requests, intensifies the acquisitional potential of the virtual company. In its extreme form one could speak of a one client segment.

- a reduction of transaction costs can be achieved if a good relationship already exists within the network. With the appearance of a market opportunity, the initiation, arrangement and control costs can be significantly reduced in this way.

There are, however, also several network-specific weaknesses in virtual organisations:

- networks can give their members less material and social security. Classical long-term working relationships will no longer exist.

- virtual organisations are highly dependent on people and therefore very susceptible to fluctuation risks.

- a network is very difficult to oversee, which brings with it the danger of overcomplexity.

\section{BUILDING UP A VIRTUAL ORGANISATION}

In order to better understand what positively or negatively influences the creation of a virtual organisation, the relationships between network nodes should be more closely examined. A line between two nodes (see Figure 1) indicates a business understanding and also a personal relationship between employees of both organisation units. This arrow contains, therefore, a freight or service flow, financial transactions and additional flows of information. This additional information serves to better co-ordination. For optimal planning, information about the respective stock levels is necessary, for example.

\subsection{Transaction costs model}

A model for the quantifying of such relationships is indicated by the transaction cost base (Williamson 1990, Figure 2). The basic thought consists of completing transactions only when the reached net advantages outweigh the transaction costs. 
Before a transaction can take place, ex ante costs come due. These are the costs for the initiation and the arrangement of a transaction:

- initiation costs: costs for an information search and the acquisition of potential transaction partners and their conditions.

- arrangement costs: costs for the negotiations of conditions and for decisionmaking.

The ex post costs arise from upholding and securing of the arranged transactions:

- adjustment costs: costs based on information asymmetry or on changing environmental factors (adjusting to the transaction conditions).

- control costs: costs to ensure adherence to the arranged deadlines, qualities, amounts, and prices.
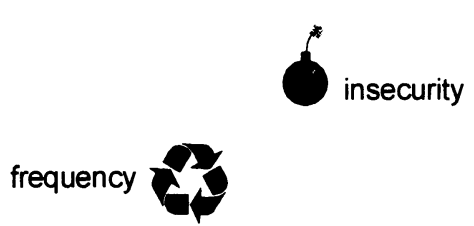

complexity



Figure 2 transaction cost model

A transaction is mainly influenced by three parameters: the insecurity, the frequency, and the complexity of a transaction. A higher complexity, a mounting insecurity and a lower frequency result in increased transaction costs, which act as a barrier to the acquisition of business relationships. These parameters can therefore also have a handicapping affect on the creation of a virtual organisation.

\subsection{Factors for success}

In order for a virtual organisation to be able to develop in a network, several elementary prerequisites must be met. Concretely the success and the development of a virtual company depends on the following factors (Schräder pp. 61-72): 
- Vision within a virtual organisation means that each participating organisational unit is clear on the job to be completed, so that client demands can be fulfilled completely. The vision must be in complete accordance with the generated service and have a supporting effect.

- Trust among the participating partners. This form of the relationship is marked by an open exchange of information, a reduced control function, the taking on of risks, keeping a certain autonomy, tolerance with regard to attempts at influence-taking, with the goal of reaching a certain temporal stability. Building up such an environment of trust is difficult and requires repeat and open communication. What is important here is that not only a few relationship promoters talk about it, but rather that each participating organisational unit takes part in the communication process.

- Distribution of knowledge takes place, when several companies collaborate together. Knowledge can, in contrast with physical objects, wander in different directions at the same time. Therefore, it is important that during an exchange of knowledge there is a balance and that the participating partners do not regard this as exploitation. As means for such knowledge distribution comprehensive teams can be used. Chrysler, for example, has recently created so-called "platform teams" for the development of automobiles.

- Information distribution can only be supported by the appropriate information and communication systems. Only the availability of such systems make it possible for a decentralised organisation to act as a unit and to seize market opportunities as quickly as possible.

\section{THE VIRTUOS PROJECT}

In order to investigate this new form of organisation in a more detailed fashion, world-wide research projects have been started. In Switzerland, the VIRTUOS project (KTI no. 3344.1) was begun in order to, among other things, test the application of this new concept especially for small and medium sized enterprises in the industrial environment.

\subsection{Project Partners}

The main partners of the VIRTUOS project are three companies from the wood industry (Figure 3). A Finnish sawmill supplies the European market with Nordic spruce. A planing factory in Austria specialises in the production of quality planed and varnished interior products. In Switzerland, these products are distributed and in part treated by another company. For the support of the conglomerate furthers partners are tied in. A JIT consulting firm will supervise the realisation based on its varied experience with reorganisation projects. The legal aspects will be investigated by an international legal firm. The processing of the relevant scientific 
and research points will be handled by the Institute for Industrial Engineering and Management (BWI) of the Swiss Federal Institute of Technology (ETH) in Zurich.

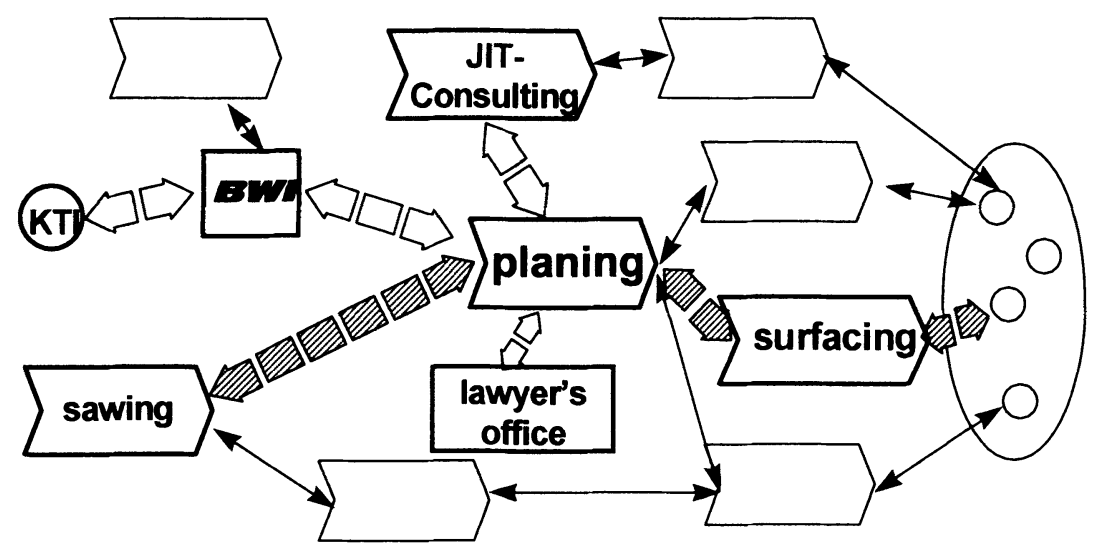

Figure 3 project configuration along the value chain

\subsection{Wood industry}

Wood is a naturally growing raw material that is only available in limited quantities. To secure its availability also in future, this raw materiel must be handled responsibly. For the realisation of a client-oriented production, special problems arise, since when clearing a forest area all felled trees must be able to be hauled away.

The wood industry is an industry with many traditional family companies, which also have an impact on its marketing structure. For a long time monopolies were in control of the Scandinavian purchasing market. The large sawmills and cellulose producers determined the price of timber. At the present time, with the integration of Scandinavia into Europe those rigid structures are breaking apart and are resulting in insecurity. Generally, it is usual for each company in the wood industry to keep a large stock on hand, in order to keep availability high in spite of market and price fluctuations. If lean times are in sight, all companies try to fill their warehouses with as much stock as possible to get through the rough period.

\subsection{The sawmill in Finland}

The company is a mid-sized producer and distributor of cut and planed wood in Finland that processes Nordic spruce from the surrounding forests. The forestry work is not carried out by the mill, but by the forestry department of a large producer of cellulose, which uses the felled leftover pieces such as the crown and 
the branches in its cellulose production. An optimal harvest of the felled timber can be influenced by determining each separate order via the computer, but the volume of raw material (i.e. beams with a specific diameter) is limited by nature. The cut raw material is felled continually each day in a quantity that is smaller than the batch size in the sawmill. Thus the production quantities, as well as the frequency of production, is limited by external factors.

The purchased timber is measured and sorted after reception in the sorting area. Throughout the cutting process the logs are cut into 4 or 2 boards, which produces at the same time sideboards of inferior quality as a bi-product. After the drying process, the boards are sorted by length and quality with the help of an automatic sorting machine.

\subsection{The planing factory in Austria}

The purchased freshly cut wood, which has a humidity of $18 \%$, is dried to $12 \%$ in in-house drying chambers as well as by an outside dryer. Before the planing process the raw materials are cut to the necessary diameter. During the planing, various textures are produced for interior or exterior use in different qualities. Only the stock size of all materials is entered in a computer, although they are sorted according to fresh cut, dry cut, split wood, and textured wood. The physical warehousing is chaotic. The fresh wood is kept outside around the warehouse, while the other materials are stacked in the open warehouse. Ground storage makes direct access for shipping difficult, therefore either the LIFO shipping principle, or no principle, is used.

\subsection{The surface treatment company in Switzerland}

The purchased textured wood is in part distributed directly and in port the surfaces are treated on two varnishing lines. Control of the surface treatment occurs according to a weekly schedule, which is made up of five steps (sales, order completion, manufacturing, buffer, shipping). The warehouse is made up of 3 halls and is used for semi-finished as well as finished products. The stock is managed by a computer system. For the preparation of the product and for shipping a separate buffer warehouse is available.

\subsection{Goals}

With the realisation of a virtual organisation along the value chain, for small and mid-size enterprises an opportunity is opening to compete against large companies. The goal of the VIRTUOS project is to make the development and application of new forms of collaboration between partner companies possible, in which in particular the concepts of virtual organisation are applied. Further, the special requirements of industry-wide planning and the necessary organisational forms should be investigated. Main points include on the one hand logistics and on the 
other the legal aspects. The participating companies naturally also want to reach specific business goals.

- Collaboration with an international pilot project in the field of virtual organisation.

- Determining the potential for staying competitive.

- Optimising the total chain (from raw material to the finished product).

- Cost reduction, cycle time reduction, augmenting flexibility.

\section{PRESENT SITUATION}

\subsection{Information flow}

The comprehensive flow of information from one enterprise to another was until a year ago restricted to an absolute minimum. At the interface points all information was passed on very sparingly. Communication was done ponderously by fax and telephone, and sales between the sawmill and the planing factory were for the most part even handled by an agent in Germany. In order to improve the situation several measures were implemented:

\section{Partner meetings}

Meetings are held quarterly between the planing factory and several selected sawmills to reduce the warehouse stock and to control seasonal fluctuations. The present warehouse stock, the order situation, and all necessary requirements are discussed. Through direct personal contact a basis of trust is established, which is very helpful in solving problems together and in searching for ideas. These measures were able to be implemented without great organisation and with little investment (travel costs).

\section{Rough planning}

In order to get enough exact market information for the whole net product chain, the sales department of the surfacing company has created an improved rough planning. In order to win clients to work together regularly during prognosis establishment, a VIP list is created as an incentive. Clients who regularly take part in the polls are added to this VIP list and profit from preferred treatment. When possible, the processed prognoses are made available to all partners.

\section{IT support}

A need for a comprehensive computing concept will be developed, that will take the different systems of the participating companies into consideration. For now the present warehouse inventory data is exchanged via e-mail. 


\subsection{Flow of material}

The material flow situation (Figure 4) is also very time consuming. The most obvious point is the enormous duration: 166 days. All indications of cycle times are average.

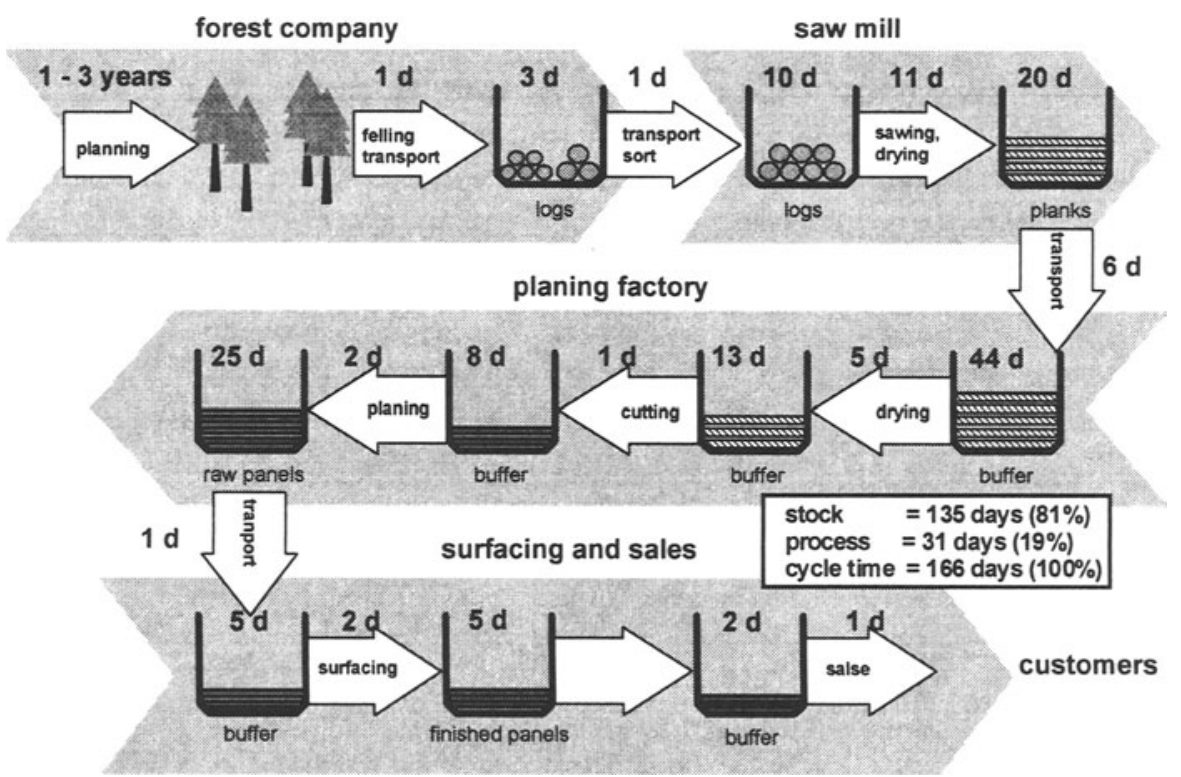

Figure 4 material flow situation

The cycle time of the identification process have for the most part already been optimised. Production is technically on a high level and arranged for flexibility in all three companies. Technically determined processing times, such as drying or external transport, which cannot be influenced, make up a large part of the processing time. In contrast, $80 \%$ of lying time takes place in the warehouse, which shows a massive savings potential. Measures were also implemented for the optimising of the flow of material:

- in purchasing the Nordic spruce, the reduction of the number of suppliers and a collaboration on a partnership basis is already being striven for. As a strategic base a supplier evaluation was made and the possibility of direct contact with suppliers was investigated.

- further, a comprehensive schedule will be implemented. Thus the companies in Austria and Switzerland can be JIT-linked, which would lead to a reduction of delivery times and to the harmonising of the order flow. 


\subsection{Organisation}

Until now it has become apparent that the idea of a virtual organisation in the wood industry makes sense. A gentlemen's agreement has already been established between the planing factory and the surfacing company, in which the division of labour is defined between production and marketing. They are striving to reach an agreement for co-operation with the suppliers by the end of the year. With the introduction of regular meetings and mutual company visits, concrete, trustbuilding measures have already been implemented.

\section{CONCLUSIONS}

Beginning with a supply network seems to be a possible starting point to build up a virtual organisation. In our project, all partners in the value chain have similar objectives. As a second advantage, every company has its specific core competence. Furthermore, in the mentioned network, there are already existing business contacts or partnerships. Building up better communications and interactions is much easier with this prerequisite. As last advantage the market pressure "helps" partnering, because the turn over in the building industry was reduced about thirty percent in one year.

Keeping the virtual aspects in mind, the VIRTUOS project will support answering the following research questions:

- How to build the ability to work in teams across borders and functions? What is the role of transaction costs?

- How are networks growing? What is the role of trust?

- Which physical attributes distinguish the virtual company from a normal company? And which products can be manufactured in a virtual company?

A generalised model is to be developed by the Institute for Industrial Engineering and Management (BWI) at ETH Zurich, using the practical application of this international business conglomerate of wood processors. This model is to be applicable to other companies and other industries. A final report about the results and answered questions is planned to publish until end of 1998.

\section{REFERENCES}

Brütsch, D., Frigo-Mosca, F. (1996): Virtuelle Organisation in der Praxis. io Management, 65:9, pp. 33-35.

McHugh, P., Merli, G., Wheeler, W.A. (1995): Beyond business process reengineering: towards the holonic enterprise. John Wiley \& Sons, Chichester, p. 12. 
Davidow, W.H., Malone, M.S. (1992): The virtual corporation. HarperCollins, New York.

Schräder, A. (1996): Management virtueller Unternehmen: organisatorische Konzeption und informationstechnische Unterstützung flexibler Allianzen. Campus Verlag, Frankfurt/Main, New York, pp. 61-72. Williamson, O.E. (1990): Die ökonomischen Institutionen des Kapitalismus: Unternehmen, Märkte, Kooperationen. J.C.B. Mohr, Tübingen.

\section{BIOGRAPHY}

David Brütsch (born in 1969) received a Master degree in industrial engineering in 1995 (Diplomierter Betriebs- und Produktionsingenieur ETHZ). At this time, he is working as research assistant in the group of Prof. P. Schönsleben at the institute of industrial engineering and management at the Federal Institute of Technology in Zürich. His main research topics are: Supply Chain Management, Business Process Reengineering, Network Logistics and Virtual Organizations. 


\section{REFERENCES}

Dangelmaier, W. (1995) Distributed Production Planning and Control in Adaptive Manufacturing Processes - The Mandate Approach, in: Improving Manufacturing Performance in a Distributed Enterprise, Advanced Systems and Tools, ed.: ESPRIT WG 9245, pp. 63-70.

Dorn, J.; Slany, W.; Stary, Ch.( 1992) Uncertainty Management by Relaxation of Conflicting Constraints in Production Process Scheduling, in: Proceedings AAAI Spring Symposium on Practical Approaches to Scheduling and Planning, Stanford, May 1992.

EU (1995) Telework Initiative 1994-5, Interact (R2085) and Palace (R2090) Projects, DG XIII, Brussels, 1995.

Fox, M.S.; Sadeh, N. (1990) Why Is Scheduling Difficult? A CSP Perspective, in: Proceedings European Conference on AI, pp. 754-767.

Grabowski, H., Renner, D.; Schmid, C. (1996) Implementation of Information Systems Supporting Engineering Processes based on World Wide Web, in: Business Process Modelling, eds: Scholz-Reiter, B.; Stickel, E., Springer, Berlin.

Gray, M.; Hudson, N.; Gordon, G. (1993) Teleworking Explained, Wiley, Chicester.

Scheer, A.W.; Nüttgens, M.; Zimmermann, V. (1995) A Framework for Integrated Business Process Management (in German), in: Wirtschaftsinformatik, Vol. 5, pp. 426-434.

Schmidt, G. (1996) Scheduling Models for Workflow Management, in: Business Process Modeling, eds: Scholz-Reiter, B.; Stickel, E., Springer, Berlin, pp. 6780.

\section{BIOGRAPHY}

Dipl.-Ing. Ortner is an assistant prof and Dr. Stary prof in business computing. Their research topics are virtual enterprises and task-oriented user interface development. 